\title{
Product Standards and Export Diversification
}

Ben Shepherd

Developing Trade Consultants, New York, USA

\begin{abstract}
This paper examines the impact of voluntary standards on trade studying textiles, clothing, and footwear sectors. It hypothesizes that internationally harmonized standards can reduce the fixed cost burden facing exporting firms, thus encouraging greater market entry and a corresponding increase in product variety on the import side. The data bear out this contention, providing the first evidence on the links between international harmonization and extensive margin trade growth. Moreover, the income level of the exporting country - as a proxy for its ability to adapt to foreign standards - has a major impact on the effect of standards. For an average low income country, a 1\% reduction in the total number of European Union standards is associated with a $0.6 \%$ increase in export variety, while a $1 \%$ increase in the proportion of European Union standards that are internationally harmonized leads to a $0.8 \%$ increase in export variety. These effects are weaker, and even reversed, for high income countries.
\end{abstract}

\footnotetext{
* Corresponding Author: Ben Shepherd; Developing Trade Consultants, 349, 5th Avenue, New York, NY 10019, USA; Tel: +1 6468459702, Fax: +1 6463500583, E-mail: Ben@Developing-Trade.com.

Acknowledgements: I am grateful to the following for helpful discussions and suggestions: Silja Baller, Chad Bown, Joe Francois, Bernard Hoekman, Benjamin Jung, Patrick Messerlin, John S. Wilson, and participants at the Midwest International Economics Meetings (Spring 2008) and Empirical Investigations in Trade and Investment (2009). This work arose out of a World Bank project on trade facilitation and development supported through a Trust Fund of the U.K. Department for International Development (http://econ.worldbank.org/projects/trade_costs). The paper was revised while the author was a Postdoctoral Research Associate at the Niehaus Center for Globalization and Governance, Princeton University. The findings, interpretations, and conclusions expressed in this paper are entirely those of the author. They do not necessarily represent the view of the World Bank, its Executive Directors, or the countries they represent.
} 
JEL Classification: F13; F14

Keywords: International Trade, Textiles, Clothing, Footwear, European Union, Product Variety, Product Standards

\section{Introduction}

Regulatory protectionism (Baldwin 2000) has the potential to impact trade by increasing the fixed product adaptation costs that firms must pay in order to access foreign markets where higher fixed costs discourage export market entry, and reduce the range of product varieties exported. This effect could be particularly strong in poor countries, where lack of access to information, technology, managerial capacity, testing and certification services, and finance can impede the ability of firms to adapt production processes quickly and adequately to meet product standards in rich country markets.

It has been suggested in the literature (Collier and Venables 2007) that trade preferences might be one way of promoting export diversification in developing countries. But such schemes focus almost exclusively on tariffs, and neglect the costs imposed by non-tariff measures (including product standards), not to mention the important role played by supply side constraints (Hoekman 2007). The costs imposed by non-tariff measures are significant, however: Kee et al. (2009) estimate that they add $70 \%$ to the level of restrictiveness imposed by tariffs alone. Complementary policies to address these costs should therefore be an important part of any renewed focus on preferences as a possible means of promoting an increase in developing country export variety.

One complementary policy that deserves further attention is the international harmonization of product standards. This paper provides empirical support for two important propositions: the negative impact of standards on foreign exporters is stronger for exporting countries with lower levels of per capita income; and those negative impacts can be attenuated through the adoption of internationally harmonized standards by importing countries.

The main novelty of this paper is its focus on the extensive (new products) margin of trade. Intuitively, the harmonization of standards can affect the extensive margin through at least two channels. On the one hand, allowing access to multiple markets 
upon compliance with a single standard and payment of just one cost is suggestive of a scale effect that would tend to impact positively on the extensive margin. However, harmonization in practice often results in adoption of a more costly standard in at least one of the harmonizing countries. This cost effect tends to work in the opposite direction, but will usually be dominated by the scale effect provided that the costs involved in harmonizing up are not too great. This paper formalizes these insights using a heterogeneous firms model of trade.

I find consistent support for a link between harmonization and the extensive margin using a new World Bank database of EU product standards in the textiles, clothing, and footwear sectors (Shepherd 2006; Czubala et al. 2007; Shepherd and Wilson 2013). These standards are issued by the European Normalization Committee (CEN). Although compliance by firms is voluntary as a matter of law (as is the case for the standards considered by Swann et al. 1996, and Moenius 2004), there is potential for these standards to have significant economic impacts: as at the end of 2006, CEN had issued 12,357 standards and approved documents and had another 3,510 in preparation. The results in this paper should therefore be seen as complementing previous work that focuses on European Community (EC) Harmonization Directives.

EU standards data are related to the export variety of partner countries using measures built up from highly detailed, 8-digit mirror data. Results show that the total number of standards in a given sector is generally negatively associated with the range of varieties exported by partner countries, but that the effect varies significantly with the exporting country's income level. For an average low income country (2003 GDP per capita $=352$ US dollars in constant 2000 US dollars), the elasticity is -0.6 , whereas for an average high income country (2003 GDP per capita $=26,410$ US dollars), the elasticity is 0.09 . The exporting country's income level appears to be a crucial determinant of its firms' ability to adapt to foreign product standards, which is consistent with the existence of impediments to investment and technology upgrades in poor countries. This result is in line with the findings of Disdier et al. (2008) for the intensive margin: product standards in agriculture tend to impact negatively on exports from developing countries to the Organization for Economic Cooperation and Development (OECD), but have little discernible impact on trade within the OECD.

In addition, I find that the degree of international harmonization of EU standards, proxied by the proportion that are identical or equivalent to International Organization for Standardization (ISO) standards, is generally positively associated with partner country export variety, but the effect again depends on the exporting country's income level. 
For an average low income country, a one percentage point increase in the proportion of harmonized standards is associated with an increase in export variety of $0.8 \%$. For an average high income country, by contrast, the impact is a decrease in export variety of $-0.7 \%$. These results are consistent with the dominance of the information transfer mechanism discussed by Moenius (2004) in the case of rich countries, but the dominance of the mechanisms discussed in this paper for many developing countries.

These results make two main contributions to the literature. First, they expand the scope of recent empirical work on trade growth at the extensive margin by examining the effects of standards and harmonization. Although the need to adapt products and production processes to meet foreign standards is often used as a motivation for including fixed market entry costs in models of international trade, this appears to be the first paper to make an empirical link between standards harmonization and extensive margin growth. Hummels and Klenow (2005) show that the bigger and richer countries tend to export a wider range of products, as do those which face lower international transportation costs. The positive extensive margin impacts of tariff liberalization and preferences are examined by Kehoe and Ruhl (2003) and Feenstra and Kee (2007).

This paper also expands the existing literature on the trade impacts of product standards both through extensive margin growth, and by an explicit examination of the partner country impacts of international harmonization. From an important early contribution on which this paper builds, Moenius (2004) uses a gravity model to show that bilaterally shared standards - and in some cases specific national standardscan promote trade. However, his results do not differentiate between standards that are internationally harmonized and those that are not. Swann et al. (1996) do make such a distinction, finding evidence that UK national standards are associated with higher levels of both exports and imports, but that the corresponding effects are much weaker in the case of internationally harmonized standards. Their results are difficult to interpret, however, since their empirical model is not supported by a detailed theoretical framework.

Two recent empirical papers have carefully examined the third-country impacts of harmonization, focusing on the intensive margin of trade. Chen and Mattoo (2008) use a sample selection gravity model to examine the impacts of EU Harmonization Directives and Mutual Recognition Agreements on intra- and extra-European trade. Baller (2007) adopts the same approach using data on both EU and Association of South-East Asian Nations (ASEAN) harmonization and mutual recognition agreements. Empirical results generally suggest that harmonization boosts trade among harmonizing countries, as 
well as imports from third countries. In particular, they suggest that some international standards agreements can increase the probability that the parties trade with each other, but can decrease the probability of trade with non-parties. The present paper builds on and extends these results by focusing on product variety, which is not the primary object of analysis in either of these two previous papers, and looking at CEN European standards rather than EC Harmonization Directives. ${ }^{1}$

The paper is organized as follows. The next section provides some theoretical motivation for the empirical hypotheses to be tested later on, using a heterogeneous firms model of trade. I provide an explicit definition of harmonization within this framework, and analyze its impacts on export product variety in harmonizing countries (insiders) and non-harmonizing countries (outsiders). Section III describes the dataset, a new World Bank database of EU product standards, as well as measures of export variety covering up to 200 countries for the period 1995 2003. The empirical model is presented in Section IV, along with estimation results and robustness checks. Section V concludes, and offers some suggestions for further research in this area.

\section{Theoretical Motivation}

This section presents a short theoretical motivation for the empirical work conducted in this paper. The Appendix presents full details, including a modeling framework that helps identify the expected effects of harmonization on insider and outsider countries, focusing exclusively on the extensive or new products margin of trade. ${ }^{2}$ To do this, I use a slightly modified version of the Chaney (2008) heterogeneous firms model. ${ }^{3}$ There are two main reasons why firm heterogeneity is potentially important in this setting. (i) It

\footnotetext{
${ }^{1}$ Under the EU's New Approach to harmonization, EC Directives are accompanied by CEN standards. However, the approach taken by Chen and Mattoo (2008) and Baller (2007) relies on an indicator of the presence or absence of a Directive, and does not directly measure the density of CEN standards that accompany them. In any case, the sectors considered in the present paper are not subject to any EC Harmonization Directives.

${ }^{2}$ The model presented here could easily be adapted to show that another likely consequence of harmonization is to increase the new markets margin of imports in the harmonizing countries. However, the data used in the empirical part of this paper are ill-suited to investigating that hypothesis because they only cover a very small number of sectors when aggregated over all countries, thus giving an insufficient number of data points for a rigorous empirical analysis. Preliminary results using this small sample (available on request) suggest that harmonization does indeed tend to increase the "new markets" margin of imports, but a detailed analysis must be left for future research.

${ }^{3}$ For a detailed discussion of the setup, solution, and equilibrium properties of this class of models, Chaney (2008).
} 
provides a rich framework for examining the trade impacts of fixed cost variables, such as product standards, and the way in which they can affect firm entry and exit decisions. (ii) There is now a wealth of case study evidence suggesting that different firms in the developing world respond to stricter foreign standards in very different ways. The discussion in World Bank (2005) and Diaz Rios and Jaffee (2008) is suggestive of a mechanism by which relatively low productivity firms contract, or even exit the market, as a result of more costly standards, whereas high productivity firms continue production. There is also evidence of sector-wide technological progress over time in some countries following the adoption of stricter standards abroad. Both dynamics are consistent with the intra-sectoral reallocation effects that lie at the core of models like Chaney (2008) and Melitz (2003).

The model considered here has three regions, and I compare two states. In the baseline state, all regions have different standards in place. Firms must pay one fixed cost per region in which they sell, which induces productivity-based sorting into markets. For each region dyad, there is a cutoff that determines the minimum level of productivity a firm must have in order to profitably ship from the producing market to the consuming market. Because the model assumes a fixed mass of potential entrants, this cutoff varies 1:1 with the mass of active firms and product varieties. As the cutoff moves downwards, and less productive firms enter the market, trade expands at the extensive margin. It is thus sufficient to analyze the effect of harmonization on the productivity cutoff in order to deduce its impact on trade growth at the new products margin.

In the harmonized state, one region adopts the standard prevailing in a second region. I show that the impact of harmonization on the productivity cutoffs depends on the interactions between a scale effect, a cost effect, and a remoteness effect. The scale effect impacts all productivity cutoffs negatively, reflecting the fact that harmonization effectively creates a single internal market comprising the two harmonizing regions. The cost effect always impacts the productivity cutoffs of the harmonizing regions (insiders) negatively, since harmonization eliminates the differential that usually exists between the cost of accessing a market as a domestic producer and the cost of accessing it as a foreign exporter. However, the cost effect's impact on non-harmonizing countries (outsiders) is strictly non-negative, since their firms must still pay at least one fixed cost in order to access both harmonized markets, in addition to the cost they need to pay to produce in their own domestic market. Finally, the remoteness effect, much like the multilateral resistance terms in Anderson and Van Wincoop (2003), picks up the fact that it is relative trade barriers that matter. In the small country case, this effect can be ignored. In 
the large country case, however, the remoteness effect impacts positively on the insiders' productivity cutoffs, because harmonization reduces their average level of trade barriers $v i s$ - -vis all countries. The effect on the outsider's productivity cutoff is ambiguous, but will also be positive under plausible assumptions.

Assuming that the remoteness effect is not too strong, the model suggests that harmonization will always be associated with extensive margin trade growth for the insider regions. Under the same assumption, the outsider region will only experience extensive margin trade growth if the market size effect outweighs the cost effect. Thus, harmonization is beneficial for outsiders at the extensive margin provided that the harmonized standard is not too much more costly to comply with that of the pre-existing national standards.

The theoretical framework set out in the Appendix extends and complements existing work in two main ways. First, I gain considerable tractability in a three country setting, as well as sharper analytical results, by adopting a Chaney (2008) model. However, Baller (2007) and Felbermayr and Jung (2008) both use variations on the Melitz (2003) theme to analyze the trade effects of product standards. Second, I focus explicitly on the extensive margin effects of product standards and harmonization, and can derive analytical results for both. Felbermayr and Jung (2008), by contrast, focus on the productivity effects of mutual recognition and what they refer to as deregulation, rather than harmonization as such. Given the prevalence of harmonization efforts, and in particular the importance of unilateral adoption of foreign or international standards in the developing world, it is useful to complement Felbermayr and Jung (2008) with a more focused treatment of harmonization.

\section{Data and Stylized Facts}

The remainder of the paper involves empirical tests of some important predictions from the model in Section II. As a preliminary, this section presents two new data sources that will be used in that work: the World Bank's EU Standards Database and measures of export variety covering up to 200 countries based on highly-detailed, 8-digit mirror (import) data from Eurostat. 


\section{A. The EU standards database}

Measuring the extent of standardization in EU product markets is not an easy business. ${ }^{4}$ Each member state sets both voluntary and mandatory standards on a national level, while centralized EU bodies also have the power to set standards with transnational application. Swann et al. (1996) and Moenius (2004) examine the trade impacts of voluntary national standards, while Chen and Mattoo (2008) and Baller (2007) focus on EC Directives. Only Czubala et al. (2007) and Shepherd and Wilson (2013) look directly at the role played by transnational voluntary standards, such as those issued by the European Committee for Standardization (CEN).

CEN is a transnational association established in 1961 by national standards bodies from all over Europe. Its standards must be adopted by all EU countries, and override any conflicting or inconsistent national standards. However, compliance with these standards is voluntary for firms. In addition to its work complementing EU Harmonization Directives, CEN is also active in independently developing standards in consultation with industry and national bodies. As noted above, CEN's output to date is substantial: 12,357 standards and approved documents, with 3,510 more in preparation. By contrast, the European Commission has issued less than two dozen Harmonization Directives under its New Approach (Pelkmans 1987). While some CEN standards effectively provide for detailed implementation of EC Directives, many of them, including the ones that I analyze here, are in sectors not covered by a Directive.

The World Bank's EU Standards Database (EUSDB) provides the first catalogue of CEN European standards in the agriculture, textiles, clothing, and footwear sectors, with mapping to a standard trade classification (HS 2000). This paper focuses exclusively on the textiles, clothing, and footwear sectors. ${ }^{5}$ From a development point of view, these sectors are particularly important since they are associated with the early stages of industrialization in many countries.

For a full overview of EUSDB's methodology, see Shepherd (2006) and Czubala et al. (2007). The general approach is similar to that of Swann et al. (1996) and Moenius (2000, 2004), although those authors both consider national standards in EU member

\footnotetext{
${ }^{4}$ For a general review of these mechanisms, see EC (2000).

${ }^{5}$ I exclude agriculture because the measure of international harmonization recorded by EUSDB (equivalence with an ISO standard) is arguably less relevant to that sector. Standards promulgated by organizations such as the Codex Alimentarius are likely to be of greater importance.
} 
states rather than CEN's EU-wide standards. ${ }^{6}$ The primary information source for EUSDB is Perinorm, ${ }^{7}$ a bibliographic database maintained jointly by the British, French, and German national standards bodies. It contains over 1.1 million records from 22 (mostly OECD) countries. Each record corresponds to a single national, regional, or international standard. For each standard, EUSDB contains data including the dates of entry into force and withdrawal, and a 1-0 dummy variable indicating whether or not it is identical or equivalent to an ISO standard. This variable is used as a proxy for de facto international harmonization. All information is cross-checked against CEN's own on-line standards catalogue, before being manually mapped to the Harmonized System product classification.

For each 2- and 4-digit HS code, EUSDB provides a count of the number of CEN standards in force in a given year over the sample period (1995 2003). ${ }^{9}$ It also counts the number of those standards that are treated as internationally harmonized using the above definition. Simple counts are used as proxies for the standards burden because Perinorm does not provide information on which to base an assessment of the relative restrictiveness of individual standards. Constructing such measures would require highly specialized technical and commercial information that is not currently available, and in any event would pose substantial problems of comparability across countries and sectors. Counts are therefore used as the best available proxy at the current time.

\footnotetext{
${ }^{6}$ An alternative approach is taken in recent papers by Fontagné et al. (2005) and Disdier et al. (2008). They use TRAINS data and country notifications to build databases of mandatory national standards. This is a promising approach, but one which currently suffers from the inconsistent reporting behavior of national authorities.

${ }^{7}$ www.perinorm.com

${ }^{8}$ http://www.cen.eu/catweb/cwsen.htm

${ }^{9}$ Counts include standards that entered into force prior to 1995 provided they were still in force at some point during the sample period. A standard is considered to be in force for a given year if it came into force before or during that year. If it is withdrawn at some point during the year, it is still assumed to be in force for the entire year. Amendments to existing standards are counted as additional standards.
} 
Table 1. Data and sources

\begin{tabular}{|l|l|c|c|c|c|c|l|}
\hline Variable & \multicolumn{1}{|c|}{ Definition } & Observations & Mean & Std. Dev. & Min. & Max. & \multicolumn{1}{|c|}{ Source } \\
\hline$\Lambda_{x s t}$ & $\begin{array}{l}\text { Export variety; } \\
\text { see formula in text. }\end{array}$ & 4,544 & 0.333 & 0.340 & 0 & 0.987 & $\begin{array}{l}\text { Eurostat; own } \\
\text { calculations. }\end{array}$ \\
\hline$s t d s_{s t}$ & $\begin{array}{l}\text { Total number of } \\
\text { EU standards. }\end{array}$ & 5,652 & 91.799 & 95.037 & 5 & 303 & EUSDB. \\
\hline${\text { is } o_{s t}}_{\text {std }_{s t}}$ & $\begin{array}{l}\text { Proportion of } \\
\text { ISO-harmonized } \\
\text { EU standards. }\end{array}$ & 5,652 & 0.386 & 0.214 & 0 & 0.649 & $\begin{array}{l}\text { EUSDB; own } \\
\text { calculations. }\end{array}$ \\
\hline$g d p p c_{x t}$ & $\begin{array}{l}\text { Per capita income } \\
\text { in constant } 2000 \\
\text { US dollars. }\end{array}$ & 4,319 & $4,351.35$ & $7,242.615$ & 56.52 & $38,403.78$ & WDI. \\
\hline$\tau_{x s t}$ & $\begin{array}{l}\text { Simple average } \\
\text { EU tariffs (applied). }\end{array}$ & 4,158 & 4.268 & 4.564 & 0 & 17 & WITS-TRAINS. \\
\hline$i m p_{s t}^{E U}$ & $\begin{array}{l}\text { Total EU import } \\
\text { value. }\end{array}$ & 5,652 & $2.36 \mathrm{E} 10$ & $1.68 \mathrm{E} 10$ & $5.24 \mathrm{E} 9$ & $5.54 \mathrm{E} 10$ & Eurostat. \\
\hline
\end{tabular}

(Notes) (i) Subscripts are used as follows: $x=$ exporter; $s=$ sector; $t=$ year.

(ii) $\Lambda_{x s t}$ has 7 zero entries and 1,108 missing entries. All regressions use $\ln \left(\Lambda_{x s t}\right)$ as the dependent variable, but results are not substantially different if $\ln \left(0.001+\Lambda_{x s}\right)$ is used instead.

(iii) Abbreviations are as follow: EUSDB: EU Standard Database; WITS-TRAINS: World Integrated Trade Solution-Trade Analysis and Information System.

Table 1 presents basic descriptive statistics, which disclose a number of notable features (Shepherd 2006, Czubala et al. 2007). All three sectors have undergone rapid growth in terms of the total number of standards in force. However, the bulk of standards remain concentrated in the textiles sector (84\%). Although the proportion of internationally harmonized standards has generally risen, the pattern across sectors is by no means uniform.

\section{B. Measuring export variety}

To examine the impact of standards and international harmonization on the extensive margin of trade, I construct new measures of export variety covering up to 200 countries. I follow the recent empirical literature on product variety in trade (Hummels and Klenow 2005, Broda and Weinstein 2006), in building on the theory-consistent measure of variety developed by Feenstra (1994). I use the version of his measure set out by 
Feenstra and Kee (2008):

$$
\Lambda_{x s t}=\frac{\sum_{l \in V_{s, t}^{x}} \overline{p_{l}^{w} q_{l}^{w}}}{\sum_{l \in V_{s}^{w}} \overline{p_{l}^{w}} q_{l}^{w}}
$$

The denominator is the total value of world exports in a particular sector, summing across all product varieties within that sector. Thus, $V_{s}^{w}$ is the full set of varieties exported in sector $s$, taking into account of all exporting countries and all time periods. Average world trade values by product variety across all years $\left(\overline{p_{l}^{w}} \overline{q_{l}^{w}}\right)$ are used to create this sum. While the denominator is invariant by exporter and time, the numerator is not. It consists of the sum of world average trade values in product varieties shipped by exporter $x$ at time $t$. The use of world average trade values ensures that variation in the numeratorand in $x$ itself-is due only to changes in $x$ 's variety set. This measure therefore has the important advantage of allowing consistent comparisons of product variety to be made across years and countries.

To implement this approach empirically, I use 8-digit import data from the European Union for the years 1995 2003. ${ }^{10}$ In line with the availability of standards data, I calculate $\Lambda$ for three sectors: textiles (HS chapters 50-60), clothing (chapters 61-63), and footwear (chapter 64). Prior to calculation, I exclude from the dataset all observations relating to internal trade among EU-15 members, as well as product codes without verbal description which correspond to residual categories covering confidential or otherwise unclassified flows. For the world average trade value $\overline{p_{l}^{w} q_{l}^{w}}$, I take the average over the sample period of import values for the EU-15, treated as a single entity.

The median variety measure in the clothing and footwear sectors $\left(\Lambda_{\text {med }}=0.2\right.$ to 0.3$)$ is noticeably higher than in textiles $\left(\Lambda_{\text {med }} \leq 0.1\right)$. However, the range in each case is very wide, running from zero to 0.8 or 0.9 . The fact that the median is so low within this range suggests that most countries export a relatively modest range of varieties in these three sectors, but that a few countries export a very wide range.

In terms of the rank ordering of countries by variety, results are broadly sensible: China, Turkey, India, and a number of countries in Central and Eastern Europe appear

\footnotetext{
${ }^{10}$ These data are freely available through the Eurostat website (http://fd.comext.eurostat.cec.eu.int/xtweb/).
} 
at the top of the list for clothing and footwear, while highly industrialized countries like Switzerland and the United States arrive in the lead for more capital intensive textiles sector. The presence of the United States and Switzerland amongst the leading countries in clothing and footwear suggests that the trade data from Eurostat may be picking up some amount of re-exports or processing trade. This is not problematic for the paper's results, however, since they are robust to the inclusion or exclusion of developed countries in the estimation sample.

\section{Empirical Model and Estimation Results}

In the remainder of the paper, I conduct empirical tests of the following three propositions:

(i) The total number of EU standards, as a proxy for the overall costs of compliance facing foreign exporters, is negatively associated with the export variety of countries outside the EU;

(ii) The proportion of EU standards that are harmonized with ISO standards, as a proxy for the degree of international harmonization, is positively associated with the export variety of countries outside the EU; and

(iii) The elasticity of export variety with respect to the total number of EU standards increases with the exporting country's income level, and the partial elasticity of export variety with respect to the proportion of harmonized decreases with the exporting country's income level.

The first of these propositions follows directly from the form of the export cutoff condition in the model set out in the Appendix. The second follows from the analysis of harmonization's impacts on outsiders, as discussed in the Appendix, assuming that remoteness effects can be ignored, and that the scale effect dominates the cost effect in the case of harmonization up. The third proposition is not directly addressed in the model, but reflects the possibility that the cost of meeting a given standard might be greater in

\footnotetext{
${ }^{11}$ Results available on request.
} 
developing than in developed countries. The model treats such costs as exogenous, but in practice they would be a function of the local availability of skilled technical labor and design sector capital (computers, high technology machine tools, etc.). It is plausible that such costs might be relatively high in developing countries because of the scarcity of these factors. Indeed, in an extreme case they might be totally absent, and would need to be imported - thus adding considerably to the costs of compliance, relative to a developed country benchmark. Firm level data collected by Maskus et al. (2005) suggest that compliance costs do in fact differ substantially across countries.

To test these hypotheses, I estimate two equations:

$$
\begin{gathered}
\ln \left(\Lambda_{x s t}\right)=\beta_{1} \ln \left(s t d s_{s t}\right)+\beta_{2} \frac{i s O_{s t}}{s t d s_{s t}}+\beta_{5} \ln \left(i m p_{s t}^{E U}\right)+\beta_{6} a t c 2_{s t}+\beta_{7} a t c 3_{s t}+\delta_{x s}+\delta_{x t}+\varepsilon_{x s t}(17) \\
\ln \left(\Lambda_{x s t}\right)=\beta_{1} \ln \left(s t d s_{s t}\right)+\beta_{2} \frac{i s O_{s t}}{s t d s_{s t}}+\beta_{3} \ln \left(s t d s_{s t}\right) * \ln \left(g d p p c_{x t}\right)+\beta_{4} \frac{i s O_{s t}}{s t d s_{s t}} \ln \left(g d p p c_{x t}\right)+\ldots \\
\ldots+\beta_{5} \ln \left(i m p_{s t}^{E U}\right)+\beta_{6} a t c 2_{s t}+\beta_{7} a t c 3_{s t}+\delta_{x s}+\delta_{x t}+\varepsilon_{x s t}
\end{gathered}
$$

Both equations are reduced forms suggested by the theoretical model developed in Section II. Equation (17) expresses partner country export variety as a function of the total cost burden of EU standards, the degree of harmonization, and a number of additional controls. I use the total value of EU imports in each sector $\left(\right.$ imp $\left._{s t}\right)$ as a proxy for sectoral expenditures $\left((1-\mu) Y_{j}\right.$ in the Appendix). Two dummies, atc 2 and atc 3 , are equal to unity for years 1998 onwards and 2002 onwards, in order to capture the effects of quota liberalization under phases two and three of implementation of the Agreement on Textiles and Clothing (ATC). ${ }^{12}$ The panel structure of the data makes it possible to control for a wide range of additional factors using fixed effects. Exporter-sector fixed effects take care of factors that are largely invariant over the time horizon considered here. Examples include comparative advantage in each of the three sectors, and long term connections with EU importers through contractual arrangements or Foreign Direct Investment (FDI), as well as sector-specific technology parameters. Exporter-year fixed

\footnotetext{
${ }^{12}$ I assume that ATC quotas apply only to the textiles and clothing sectors as defined here, and not to footwear. This is basically consistent with the product list in the Annex to the ATC, which has extensive coverage in HS chapters 50-63, but lists only three 6-digit product lines in Chapter 64 .
} 
effects control for changes in the level of industrial or institutional development, countryspecific macroeconomic or policy shocks, as well as technological change affecting all three sectors but specific to each exporting country where such changes being highly likely due to the interlinkages that exist among the sectors.

\section{A. Baseline estimation results}

Table 2. Regression results

\begin{tabular}{|c|c|c|c|c|c|c|}
\hline & \multicolumn{2}{|c|}{ Baseline } & \multicolumn{2}{|c|}{ First Lags } & \multicolumn{2}{|c|}{ Second Lags } \\
\hline $\ln \left(s t d s_{s t}\right)$ & $\begin{array}{c}-0.415^{* * *} \\
{[0.143]}\end{array}$ & $\begin{array}{c}-1.574 * * * \\
{[0.473]}\end{array}$ & $\begin{array}{c}-0.1 \\
{[0.169]}\end{array}$ & $\begin{array}{c}-2.228 * * * \\
{[0.462]}\end{array}$ & $\begin{array}{c}0.05 \\
{[0.162]}\end{array}$ & $\begin{array}{c}-1.415^{* * *} \\
{[0.529]}\end{array}$ \\
\hline$\frac{i s o_{s t}}{s t d s_{s t}}$ & $\begin{array}{l}0.665^{*} \\
{[0.376]}\end{array}$ & $\begin{array}{l}2.903 * * \\
{[1.452]}\end{array}$ & $\begin{array}{c}-0.08 \\
{[0.346]}\end{array}$ & $\begin{array}{c}5.059 * * * \\
{[1.348]}\end{array}$ & $\begin{array}{c}-0.15 \\
{[0.336]}\end{array}$ & $\begin{array}{l}1.28 \\
{[1.471]}\end{array}$ \\
\hline $\ln \left(s t d s_{s t}\right)^{*} \ln \left(g d p p c_{x t}\right)$ & & $\begin{array}{c}0.163 * * * \\
{[0.057]}\end{array}$ & & $\begin{array}{c}0.256^{* * *} \\
{[0.055]}\end{array}$ & & $\begin{array}{c}0.172^{* * *} \\
{[0.065]}\end{array}$ \\
\hline$\frac{i s o_{s t}}{s t d s_{s t}} * \ln \left(g d p p c_{x t}\right)$ & & $\begin{array}{c}-0.355^{* *} \\
{[0.176]}\end{array}$ & & $\begin{array}{c}-0.619^{* * *} \\
{[0.164]}\end{array}$ & & $\begin{array}{c}-0.24 \\
{[0.182]}\end{array}$ \\
\hline $\ln \left(i m p_{s t}^{E U}\right)$ & $\begin{array}{c}0.608^{* * *} \\
{[0.224]}\end{array}$ & $\begin{array}{c}0.982 * * * \\
{[0.229]}\end{array}$ & $\begin{array}{c}0.997 * * * \\
{[0.232]}\end{array}$ & $\begin{array}{c}0.848^{* * *} \\
{[0.227]}\end{array}$ & $\begin{array}{c}0.772 * * * \\
{[0.217]}\end{array}$ & $\begin{array}{c}0.996 * * * \\
{[0.210]}\end{array}$ \\
\hline Number of observations & 4,537 & 3,792 & 4,038 & 3,380 & 3,531 & 2,967 \\
\hline Number of countries & 187 & 167 & 187 & 166 & 187 & 166 \\
\hline $\mathrm{R}^{2}$ & 0.71 & 0.71 & 0.73 & 0.74 & 0.75 & 0.76 \\
\hline
\end{tabular}

(Notes) (i) All regressions use $\ln \left(\Lambda_{x s}\right)$ as the dependent variable. Regressions in columns 1 and 2 use current values of $s t d s_{s t}$ and $\frac{i s S_{s t}}{s t d s_{s t}}$, columns 3-4 use $L . s t d s_{s t}$ and $L . \frac{i s O_{s t}}{s t d s_{s t}}$, and columns 5-6 use $L^{2} . s t d s_{s t}$ and $L^{2} \cdot \frac{i s O_{s t}}{s t d s_{s t}}$.

(ii) All models include fixed effects by exporter-sector and exporter-year. All models include dummy variables for the second and third phases of ATC liberalization (not reported). Robust standard errors appear in square brackets under the coefficient estimates.

(iii) *denote statistically significant at $10 \%, * *$ denote statistically significant at $5 \%, * * *$ denote statistically significant at $1 \%$.

Table 2 presents the baseline estimation results using OLS. ${ }^{13}$ In column 1 , the total

\footnotetext{
${ }^{13}$ Export variety $\Lambda_{x y t}$ has seven zero entries and 1108 missing entries, which should be treated as zero. All regressions use $\ln \left(\Lambda_{x s}\right)$ as
} 
count of EU standards enters with a negative coefficient, and is statistically significant at the $1 \%$ level. By contrast, the proportion of standards that are internationally harmonized carries a positive coefficient that is statistically significant at the $10 \%$ level. In terms of magnitude, column 1 suggests that a 1\% increase in the total number of standards is associated with a $-0.4 \%$ decrease in partner country export variety, while a one percentage point increase in the proportion of internationally harmonized standards is associated with a $0.7 \%$ increase in export variety. Both results are in line with the expectations based on the theoretical framework outlined in Section II. Similarly, the coefficient on total EU imports is also positive and statistically significant at the $1 \%$ level, and suggests a reasonable (0.6) elasticity of the extensive margin with respect to the market size in the importing region.

Column 2 of Table 2 shows that inclusion of per capita income interaction terms captures an important dimension of the data. The coefficient on $s t d s_{s t}$ remains negative and $1 \%$ significant, while its interaction term is positive and $1 \%$ significant. The impact of importer product standards on partner country export variety thus depends crucially on the development level of the exporting country: for an average low income country (2003 GDP per capita $=352$ US dollars) the elasticity is -0.6 , whereas for an average high income country (2003 GDP per capita $=26,410$ US dollars) the elasticity is 0.09 . So while standards have only a very weak, and possibly positive, impact on the export variety of developed countries, they have a strongly negative impact on the export variety of poor countries.

The opposite dynamic is apparent in the case of harmonization. Including the interaction terms, in fact, leads to stronger results in terms of statistical significance. In column 2, the coefficient on $\frac{i s o_{s t}}{s t d s_{s t}}$ is positive and 5\% significant, while the interaction term is negative and 5\% significant. As for standards, the impact of harmonization on partner country export variety also depends crucially on the exporter's development level: for an average low income country, a one percentage point increase in the proportion of internationally harmonized standards is associated with an increase in export variety of $0.8 \%$, while for an average high income country the impact is a decrease in export variety of $0.7 \%$. The result for developing countries is consistent with the predictions made in Section II, but the negative impact on developed countries appears, on its face,

the dependent variable, but results only differ marginally if $\ln \left(0.001+\Lambda_{x s}\right)$ is used instead. In part, this is due to other data being missing for countries with a substantial number of zero entries, which has the effect of restricting the sample. Also, results are robust to estimation using Tobit instead of OLS. Estimation using the fractional logit model produces a coefficient on standards that is negative and statistically significant, and a coefficient on the proportion of ISO standards that is positive, as expected, but statistically insignificant. 
to be more difficult to explain.

In fact, the previous literature contains a number of similar results. Using a developed country sample, Swann et al. (1996) find results that are generally consistent with a traderestricting impact of internationally harmonized standards relative to national standards. Moenius (2004) finds that in some sectors, bilaterally harmonized standards are trade restricting. Both papers suggest an explanation for these findings in terms of information effects: harmonized standards by their nature cannot inform foreign producers as to the state of demand or consumer preferences in the importing country. Although the data do not at this stage permit a definitive conclusion, it is possible that this mechanism tends to dominate other effects for developed countries that are relatively unconstrained in terms of the financial and technological requirements of adaptation to product standards, and which may export high quality products where information on consumer preferences is particularly important.

\section{B. Robustness checks}

To ensure the robustness of the baseline results, I conduct additional checks in three dimensions: accounting for the potential endogeneity of product standards; controlling for additional confounding factors related to trade policy in textiles, clothing, and footwear; and comparing results across alternative country samples.

\section{Endogeneity}

Previous work has alluded to the possibility that product standards could be endogenous to trade, for instance through a political economy process. In an environment where tariffs are bound through the World Trade Organization (WTO) system, local producers might use unduly costly standards as a means of raising rivals' costs (Fischer and Serra 2000, Ganslandt and Markusen 2001). There are suggestions in the literature that such an effect may be relevant empirically (Essaji 2005, Kono 2006), but the evidence presented at this stage is relatively weak. Intuitively, it seems less likely that such a dynamic exists in relation to partner country export variety than for total trade flows. Nonetheless, I re-estimate the baseline model with and without interaction terms using first and second lags of the standards variables, since they should be exogenous with respect to current export variety.

Columns 3-6 of Table 2 present results. Interestingly, the regressions with income 
per capita interaction terms perform much better than those without. In the model with first lags, the coefficients on $s t d s_{s t}, \frac{i s o_{s t}}{s t d s_{s t}}$ and the two interaction terms have the same signs as in the baseline regression, and are 1\% significant. Since all coefficients increase markedly in absolute value terms, it can be said that using first lags leads to results that are stronger in terms of both statistical and economic significance. In the case of second lags, results remain consistent with the baseline, but are somewhat weaker. The coefficient on stds $s_{s t}$ is negative and its interaction term is positive, while the reverse is true for $\frac{i s o_{s t}}{s t d s_{s t}}$. However, only the standards coefficients are statistically significant at conventional levels (1\%). ${ }^{14}$ For the models without interaction terms, no coefficients are statistically significant, and all but one carry unexpected signs.

Overall, the results using lagged standards terms are very similar to those obtained in the baseline model, at least in the case of the model with per capita income interactions. I interpret them as indicating that endogeneity is unlikely to be a major issue in this case. This result accords with the findings of Moenius (2004) using five year lags of standards, and of Chen and Mattoo (2008) using harmonization in similar sectors as an instrument for harmonization. In addition, the results with lagged standards terms again highlight the importance of allowing for standards to have different effects according to the development level of the exporting country.

${ }^{14}$ The coefficient on the $\frac{i s o_{s t}}{s t d s_{s t}}$ interaction term is significant at the $20 \%$ level, probability $=0.192$. 


\section{Accounting for the impacts of trade policy}

Table 3. Robustness checks

\begin{tabular}{|c|c|c|c|c|c|c|c|c|}
\hline \multirow[b]{2}{*}{$\ln \left(s t d s_{s t}\right)$} & \multicolumn{2}{|c|}{ Tariffs } & \multicolumn{2}{|c|}{ No Quota } & \multicolumn{2}{|c|}{ No RTA } & \multicolumn{2}{|c|}{ No ACP } \\
\hline & \begin{tabular}{c|}
$-0.368^{* *}$ \\
{$[0.146]$}
\end{tabular} & $\begin{array}{c}-1.442 * * * \\
{[0.473]}\end{array}$ & $\begin{array}{c}-0.481 * * * \\
{[0.167]}\end{array}$ & $\begin{array}{c}-1.687^{* * *} \\
{[0.543]}\end{array}$ & {$\left[\begin{array}{r}-0.441^{* * *} \\
{[0.159]}\end{array}\right.$} & $\begin{array}{c}-1.587 * * * \\
{[0.512]}\end{array}$ & $\begin{array}{c}-0.22 \\
{[0.143]}\end{array}$ & $\begin{array}{c}-0.45 \\
{[0.400]}\end{array}$ \\
\hline$\frac{i s o_{s t}}{s t d s_{s t}}$ & \begin{tabular}{c|c}
0.45 & \\
{$[0.370]$} &
\end{tabular} & \begin{tabular}{l|l}
$2.656^{*}$ & \\
{$[1.466]$} &
\end{tabular} & $\begin{array}{l}0.773^{*} \\
{[0.438]}\end{array}$ & $\begin{array}{l}3.048^{*} \\
{[1.643]}\end{array}$ & $\begin{array}{l:l}0.721^{*} & \\
{[0.411]} & \end{array}$ & \begin{tabular}{l|l}
$2.872 *$ & \\
{$[1.586]$} &
\end{tabular} & $\begin{array}{c}0.54 \\
{[0.385]}\end{array}$ & $\begin{array}{c}0.64 \\
{[1.323]}\end{array}$ \\
\hline $\ln \left(s t d s_{s t}\right)^{*} \ln \left(g d p p c_{x t}\right)$ & & $\begin{array}{c}0.146^{* *} \\
{[0.057]}\end{array}$ & & $\begin{array}{c}0.170^{* * *} \\
{[0.065]}\end{array}$ & & \begin{tabular}{c|}
$0.159 * *$ \\
{$[0.063]$}
\end{tabular} & & $\begin{array}{c}0.05 \\
{[0.045]}\end{array}$ \\
\hline$\frac{i s o_{s t}}{s t d s_{s t}} * \ln \left(g d p p c_{x t}\right)$ & & \begin{tabular}{l|l}
$-0.320^{*}$ & \\
{$[0.178]$} &
\end{tabular} & & $\begin{array}{l}-0.372 * \\
{[0.198]}\end{array}$ & & \begin{tabular}{l|l}
$-0.342^{*}$ & \\
{$[0.196]$} &
\end{tabular} & & $\begin{array}{c}-0.09 \\
{[0.154]}\end{array}$ \\
\hline $\ln \left(i m p_{s t}^{E U}\right)$ & $\begin{array}{c}0.725^{* * *} \\
{[0.239]}\end{array}$ & $\begin{array}{l}1.014 * * * \\
{[0.244]}\end{array}$ & $\begin{array}{l}0.718^{* * *} \\
{[0.256]}\end{array}$ & \begin{tabular}{c|c}
$1.147^{* * *}$ & \\
{$[0.263]$} &
\end{tabular} & $\begin{array}{l}0.712 * * * \\
{[0.247]}\end{array}$ & $\begin{array}{c}1.059 * * * \\
{[0.257]}\end{array}$ & $\begin{array}{c}0.32 \\
{[0.211]}\end{array}$ & $\begin{array}{c}0.641 * * * \\
{[0.190]}\end{array}$ \\
\hline $\ln \left(1+\tau_{x s t}\right)$ & \begin{tabular}{c|c}
-0.06 & \\
{$[0.116]$} &
\end{tabular} & \begin{tabular}{c|c}
0.05 & \\
{$[0.105]$} &
\end{tabular} & & & & & & \\
\hline Number of observations & 4,023 & 3,607 & 4,159 & 3,450 & 4,116 & 3,421 & 3,093 & 2,407 \\
\hline Number of countries & 182 & 166 & 187 & 167 & 175 & 157 & 113 & 96 \\
\hline $\mathrm{R}^{2}$ & 0.71 & 0.72 & 0.71 & 0.71 & 0.71 & 0.71 & 0.77 & 0.81 \\
\hline
\end{tabular}

(Notes) (i) All regressions use $\ln \left(\Lambda_{x s t}\right)$ as the dependent variable. Regressions in columns 1-2 use the full sample, columns 3-4 exclude countries subject to ATC quotas, columns 5-6 exclude countries having a regional trade agreement with the EU, and columns 7-8 exclude the African, Caribbean, and Pacific group of countries.

(ii) All models include fixed effects by exporter-sector, and exporter-year. All models include dummy variables for the second and third phases of ATC liberalization (not reported). Robust standard errors appear in square brackets under the coefficient estimates.

(iii) * denote statistically significant at $10 \%$, ** denote statistically significant at $5 \%$, *** denote statistically significant at $1 \%$.

(iv) Abbreviations are as follows: $\mathrm{ACP}=\mathrm{African}$, Caribbean and Pacific Group of States; $\mathrm{RTA}=$ Regional Trade Agreement.

The baseline models already account in part for the potential impacts of EU trade policy by including dummies for the second and third phases of ATC liberalization, which occurred during the sample period that the model deals with. However, there are two additional dimensions that need to be explored. First, I include WITS-TRAINS data on applied bilateral tariffs. ${ }^{15}$ Results in columns 1-2 of Table 3 are very close to the

\footnotetext{
${ }^{15}$ These data are not included in the baseline model because they significantly restrain the estimation sample. This is due to a lack of
} 
baseline, although there is a slight loss of statistical significance in some cases: $\frac{i s o_{s t}}{s t d s_{s t}}$ is not significant in the model without interaction terms, and in the model with interactions both terms are 10\% significant compared with $5 \%$ in the baseline. The coefficient on tariffs is not statistically significant in either regression, and only has the expected negative sign in column 1 (no interactions). This contrasts with other work on export variety, which tends to suggest that tariffs can have a significant negative impact (Feenstra and Kee 2007).

There are two likely reasons for the difference in this case. First, during the sample period the main trade distortions in the sectors under consideration here came from non-tariff barriers, particularly quotas. Second, TRAINS has only partial coverage of preferential tariff rates over the sample period, which is potentially important given the role of regional agreements and development-related preferences in these sectors.

As an additional check, I exclude from the estimation sample those countries that were subject to quotas under the ATC regime (columns 3-4 of Table 3). The response of firms in those countries to changes in the number and type of EU standards would have potentially been constrained by these quotas, and this mechanism could conceivably impact results from the baseline models. However, estimation results suggest that this is in fact not a major problem. Results in terms of sign are identical to the baseline, although the coefficients on $\frac{i s o_{s t}}{s t d s_{s t}}$ and its interaction term change from $5 \%$ significance in the baseline to $10 \%$ significance in the model without ATC quota countries. Interestingly, all coefficients are slightly larger in absolute value than under the baseline, suggesting that the existence of quotas might indeed have acted to constrain somewhat the export variety response of some of the EU's trading partners.

\section{Alternative country samples}

It is also important to ensure that results are robust to the use of different country samples. In particular, this method can be used to exclude the influence that regional or preferential trade agreements might have on export variety, other than through channels such as tariffs. For instance, favorable rules of origin might be an additional factor influencing trade growth at the extensive margin in this sector (De Melo and Portugal Perez 2009). I therefore rerun the baseline models excluding all countries that are party to a regional trade agreement with the EU, and then all countries in the African,

\footnotetext{
data availability.

${ }^{16}$ Data on regional agreements come from http://www.worldtradelaw.net/fta/ftadatabase/ftas.asp, supplemented by information from http://rade.ec.europa.eu/doclib/docs/2006/december/tradoc_111588.pdf.
} 
Caribbean, and Pacific group of countries. ${ }^{17}$

Results are in columns 5-8 of Table 3. Excluding the EU's Regional Trade Agreement (RTA) partners (columns 5-6) makes very little difference to the results: the coefficients on standards, harmonization, and both sets of interaction terms carry the same signs, have similar magnitudes, and remain statistically significant at the $10 \%$ level or better. Exclusion of the African, Caribbean and Pacific Group of States (ACP) countries, on the other hand, causes the coefficients on standards and harmonization to become significant at the $15 \%$ and $20 \%$ levels respectively (probability $=0.133$ and 0.164 ), although their signs remain in line with expectations, and their magnitudes are similar to those of the baseline. However, exclusion of the ACP countries from the model with interaction terms results in a loss of statistical significance for all coefficients, even though they retain the expected signs. They are much smaller in absolute value than under the baseline. The likely reason for these results is that the ACP classification covers the vast majority of the poorer developing countries. As a result, the variance in per capita GDP for the sub-sample without the ACPs is much smaller than for the full sample. The unique variation in the interaction terms is correspondingly less, which makes it difficult to identify independent effects in levels and interactions. However, the results from the model without interaction terms suggest that the main insights from the baseline model continue to apply even when the ACP countries are excluded from the estimation sample.

\section{Conclusions}

This paper has provided the first direct empirical evidence that while the overall impact of product standards is negative on partner country export variety, harmonization to international standards can act as an important mitigating factor. It has also shown that the strength of these effects depends crucially on the exporting country's development level. For an average low income country, the elasticity of export variety with respect to the total number of European Union (EU) standards is -0.6 , whereas for an average high income country it is 0.09 . The effect of a one percentage point increase in the proportion

\footnotetext{
${ }^{17}$ The list of ACP countries comes from http://ec.europa.eu/development/Geographical/RegionsCountries_en.cfm.
} 
of EU standards that are harmonized with international standards is associated with an increase in export variety of $0.8 \%$ in an average low income country, but a decrease of $-0.7 \%$ in an average high income country. These results have proved highly robust to the use of lagged standards data as a check against endogeneity bias, the inclusion of additional trade policy variables, and estimation using sub-samples excluding countries that were bound by quotas under the Agreement on Textiles and Clothing (ATC), are parties to an Regional Trade Agreement (RTA) with the EU, as well as the African, Caribbean and Pacific Group of States (ACP) countries.

These are significant findings given the importance of the textiles, clothing, and footwear sectors to economies in their early stages of industrialization. Based on a heterogeneous firms framework, these results would tend to suggest that harmonization can be an effective way of promoting foreign market access for firms with lower productivity than incumbent exporters, since it induces a downwards shift in the export productivity cutoff. International harmonization could therefore be expected to encourage exports by small and medium enterprises in developing countries - a prediction that future work using firm level data could test. Importing countries looking to provide impetus to non-traditional exports from developing countries could perhaps use international standards harmonization as a complement to more generous tariff preferences and more open rules of origin.

In policy terms, this paper's results are important due to the role of internationally harmonized standards in the world trading system. The World Trade Organization (WTO) agreements encourage, but do not require, member countries to use international standards. This work suggests that such an emphasis is appropriate, and could even be reinforced: using international standards effectively improves market access opportunities for developing countries. In addition, these results highlight the importance of voluntary standards, which occupy an ambiguous place in the WTO agreements. The agreements apply primarily to mandatory standards. However, voluntary standards, whether harmonized or not, can also have significant trade effects that need to be taken into account. Further work on a policy level to deal with the trade effects of voluntary standards is therefore warranted.

An alternative way of interpreting the results presented here is in terms of export diversification, an important policy issue for many developing countries. By equating variety growth and diversification, a case can be made that international standards harmonization could be one way in which large, rich country import markets could help support export diversification in developing countries. These results therefore 
complement recent work on diversification, which has highlighted the importance of policies such as trade facilitation (Dennis and Shepherd 2011).

This paper's policy implications, in combination with those from previous work using similar data, can be summarized as follows:

- Mandatory and voluntary standards can both have implications for world trade because they alter firms' production costs, either de jure or de facto.

- International differences in standards can increase the costs for firms, and thereby restrict trade. However, differences can be a legitimate response to different national circumstances and preferences.

- Harmonization of standards is one way of eliminating international differences in standards. Standards harmonization can be beneficial to exporters within the harmonizing region, and, under certain circumstances, to exporters from other regions. However, harmonization is not always beneficial, in particular if it results in a very costly standard being adopted.

- One way of ensuring that regional standards harmonization, such as that undertaken in the EU, is to harmonize regional standards with international standards, such as those issued by the International Organization for Standardization (ISO).

- Harmonized EU standards that are consistent with ISO norms are seen as less trade restrictive than non-ISO consistent standards by the countries outside the EU.

- These implications are particularly important for developing countries, where firm competitiveness can be a serious obstacle to exporting.

- In addition to promoting trade at the intensive margin, standards harmonization can also, under the right circumstances, promote it at the extensive margin. This finding is particularly important for developing countries, because it means that overseas standards harmonization - in particular if it is consistent with ISO norms - can help promote export diversification.

The main obstacle to future empirical work in the area of product standards and their trade effects is the limited data availability. While the World Bank's EU Standards Database provides information on the textiles, clothing, and footwear sectors, there is clearly a need to expand on this in terms of both geographical and sectoral scope. Future work with an expanded dataset could investigate the possibility that international harmonization might also impact geographical export diversification, an important dimension of extensive margin growth that could not be examined here. 
Received 28 September 2013, Revised 5 November 2014, Accepted 16 April 2015

\section{References}

Allen Dennis and Ben Shepherd. "Trade Costs, Barriers to Entry, and Export Diversification in Developing Countries." The World Economy 34(1) (2011): 101-122.

Baldwin, Richard E., "Regulatory Protectionism, Developing Nations, and a Two-Tier World Trade System" in Susan M. Collins and Dani Rodrik (eds.), Brookings Trade Forum 2000, Washington, D.C.: Brookings Institution Press.

Baller, Silja, "Trade Effects of Regional Standards Liberalization: A Heterogeneous Firms Approach.”, Policy Research Working Paper No. 4124, The World Bank (2007).

Ben Shepherd (2006), "The EU Standards Database: Overview and User Guide." Mimeo, http://siteresources.worldbank.org/INTRES/Resources/469232-1107449512766/ EUSDB_Overview_UserGuide_021306.pdf.

Ben Shepherd and Norbert Wilson. "Product Standards and Developing Country Agricultural Exports: The Case of the European Union." Food Policy 42 (October) (2013): 1-10.

Bernard Hoekman. "Doha, Development, and Discrimination." Pacific Economic Review 12(3) (2007): 267-292.

Broda, Christian, and David E. Weinstein, "Globalization and the Gains from Variety.", The Quarterly Journal of Economics, 121(2) (2006): 541-585.

Chaney, Thomas, "Distorted Gravity: The Intensive and Extensive Margins of International Trade.", American Economic Review, 98(4) (2008): 1707-1721.

Chen, Maggie Xiaoyang, and Aaditya Mattoo, "Regionalism in Standards: Good or Bad for Trade?", Canadian Journal of Economics, 41(3) (2008): 838-863.

Collier, Paul, and Anthony J. Venables, "Rethinking Trade Preferences: How Africa Can Diversify its Exports.”, Discussion Paper No. 6262, CEPR (2007).

Czubala, Witold, Ben Shepherd, and John S. Wilson, Forthcoming, "Help or Hindrance? The Impact of Harmonized Standards on African Exports.", Journal of African 


\section{Economies.}

Daniel Kono. "Optimal Obfuscation: Democracy and Trade Policy Transparency." American Political Science Review 100 (3) (2006): 369-384.

David Hummels and Peter Klenow. "The Variety and Quality of a Nation's Exports." The American Economic Review 95 (3)(2005): 704-723.

De Melo, Jaime, and Alberto Portugal-Perez, "Rules of Origin, Preferences, and Diversification in Apparel: African Exports to the US and to the EU.", Discussion Paper No. 7072, CEPR (2009).

Diaz Rios and Jaffee, "Luz Diaz Rios and Steven Jaffee. "Barrier, Catalyst, or Distraction? Standards, Competitiveness, and Africa's Groundnut Exports to Europe." Agriculture and Rural Development Discussion Paper No. 39, World Bank (2008).

Disdier et al. Anne-Célia Disdier, Lionel Fontagné, and Mondher Mimouni. "The Impact of Regulations on Agricultural Trade: Evidence from SPS and TBT Agreements." American Journal of Agricultural Economics 90 (2) (2008): 226-250.

Essaji. Azim Essaji. “The Political Economy of Technical Regulations.” Mimeo (2005), www.wlu.ca/documents/6388/pol_econ_tr.pdf.

European Commission, "Guide to the Implementation of Directives Based on the New Approach and the Global Approach." (2000) http://europa.eu.int/comm/enterprise/ newapproach/newapproach.htm.

Gabriel Felbermayr and Benjamin Jung. "Sorting it Out: Technical Barriers to Trade and Industry Productivity." Working Paper No. 014, FIW (2008).

Hiau-Looi Kee, Alessandro Nicita, and Marcelo Olarreaga. "Estimating Trade Restrictiveness Indices.", Policy Research Working Paper No. 3840, The World Bank (2006).

Jacques Pelkmans. "The New Approach to Technical Harmonization and Standardization.” Journal of Common Market Studies 25 (3) (1987): 249-269.

James Anderson and Eric Van Wincoop. "Gravity with Gravitas: A Solution to the Border Puzzle." American Economic Review, 93 (1) (2003): 170-192.

Johannes Moenius. "Information Versus Product Adaptation: The Role of Standards in Trade." International Business and Markets Research Center Working Paper, 
Northwestern University (2004).

Johannes Moenius. "The BISTAN Data Retrieval Reference." Working Paper, University of California at San Diego (2000).

Keith Maskus, Tsunehiro Otsuki, and John Wilson. "The Cost of Compliance with Product Standards for Firms in Developing Countries: An Econometric Study." Policy Research Working Paper No. 3590, The World Bank (2005).

Lionel Fontagné, Friedrich von Kirchbach, and Mondher Mimouni. “An Assessment of Environmentally-Related Non-Tariff Measures." The World Economy 28 (10) (2005): 1417-1439.

Marc Melitz. "The Impact of Trade on Intra-Industry Reallocations and Aggregate Industry Productivity." Econometrica 71 (6)(2003): 1695-1725.

Mattias Ganslandt and James Markusen, "Standards and Related Regulations in International Trade: A Modeling Approach.” Working Paper No. 8346, NBER (2001).

Neil Gandal and Oz Shy. "Standardization Policy and International Trade." Journal of International Economics 53(2001): 363-383.

Patrick Royston and Nicholas Cox. "A Multivariable Scatterplot Smoother." Stata Journal 5 (3) (2005): 405-412.

Peter Swann, Paul Temple, and Mark Shurmer. "Standards and Trade Performance: The UK Experience.” The Economic Journal 106 (438)(1996): 1297-1313.

Robert Feenstra and Hiau Looi Kee. "Trade Liberalization and Export Variety: A Comparison of Mexico and China.” The World Economy 30 (1) (2007): 5-21.

Robert Feenstra. "New Product Varieties and the Measurement of International Prices." The American Economic Review 84 (1) (1994): 157-177.

Ronald Fisher and Pablo Serra. "Standards and Protection." Journal of International Economics 52(2000): 377-400.

Robert Feenstra and Hiau Looi Kee. "Export Variety and Country Productivity: Estimating the Monopolistic Competition Model with Endogenous Productivity." Journal of International Economics 74 (2) (2008): 500-518.

Timothy Kehoe and Kim Ruhl. "How Important is the New Goods Margin in 
International Trade.” Research Department Staff Report No. 324, Federal Reserve Bank of Minneapolis (2003).

World Bank. Food Safety and Agricultural Health Standards: Challenges and Opportunities for Developing Country Exports. Washington, D.C.: The World Bank (2005). 
Table 4. Theoretical predictions of the effects of harmonization

\begin{tabular}{|l|l|l|}
\hline \multirow{4}{*}{ Initial Conditions } & Harmonization Across & Harmonization Up \\
\hline \multirow{4}{*}{ Insider Productivity Cutoff } & $f_{F F}=f_{R R}$ & $f_{F F}<f_{R R}$ \\
\cline { 2 - 3 } & $f_{H F}=f_{H R}$ & $f_{H F}<f_{H R}$ \\
\cline { 2 - 3 } & Scale Effect $<0$ & Scale Effect $<0$ \\
\cline { 2 - 3 } & Cost Effect $<0$ & Cost Effect $<0$ \\
\cline { 2 - 3 } & Remoteness Effect $>0$ & Remoteness Effect $>0$ \\
\hline \multirow{5}{*}{ Outsider Productivity Cutoff } & Scale Effect $<0$ & Scale Effect $<0$ \\
\cline { 2 - 3 } & Cost Effect $=0$ & Cost Effect $>0$ \\
\cline { 2 - 3 } & Remoteness Effect $>0$ & Remoteness Effect $<>0$ \\
\hline
\end{tabular}

(Notes) (i) See the Appendix for a full description of the model, parameters, and harmonization effects.

(ii) Harmonization in all cases is defined as adoption by region $F$ of region $R$ 's standard. Following harmonization, producers in $F$ and $R$ can access the combined market upon payment of the fixed cost $f_{R R}$, while producers in $H$ must pay $f_{H R}$.

Figure 1. Non-parametric (Lowess) regression of $\bar{\Lambda}_{x s t}$ on stds st and iso $o_{s t}$
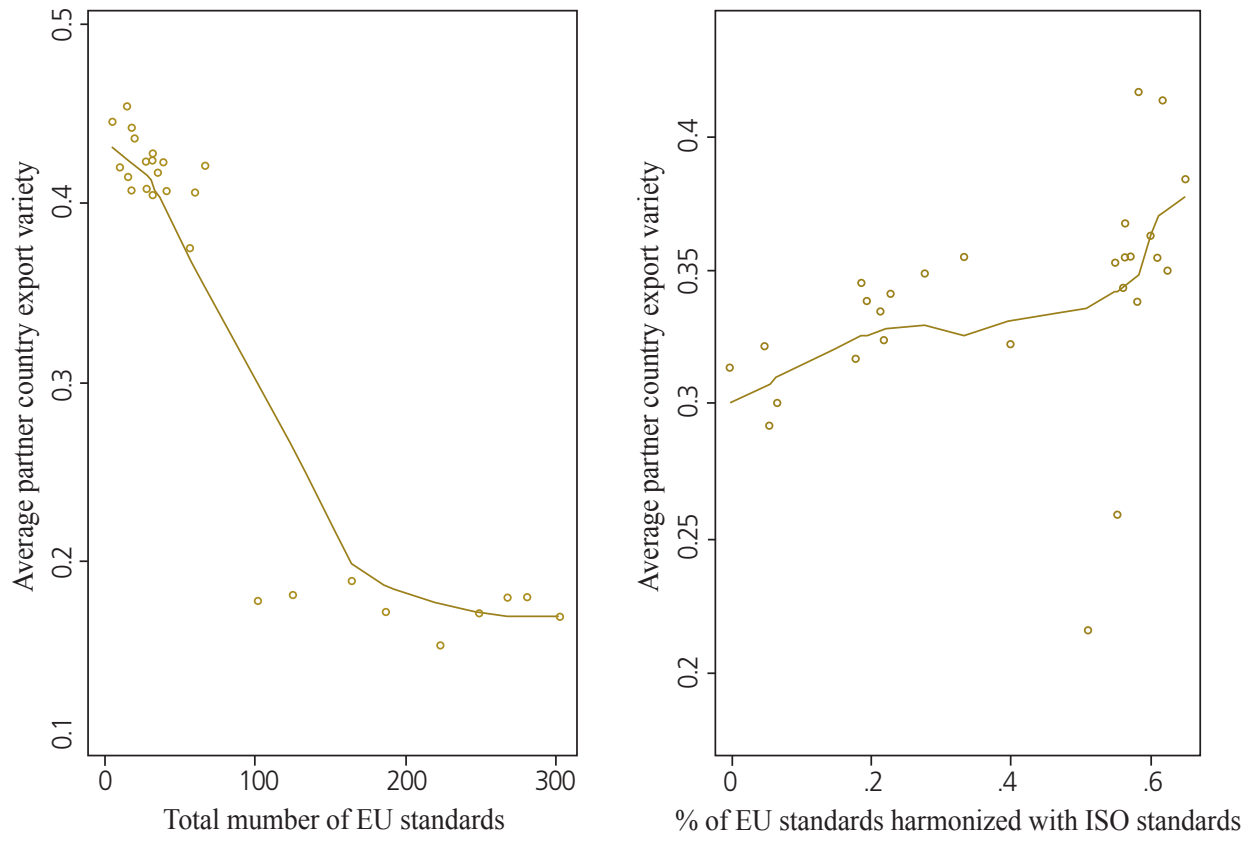


\section{Appendix}

This Appendix more fully develops the intuition presented in Section II.

\section{A. Model Setup}

The world consists of three regions, Home $(H)$, Foreign $(F)$, and Rest of the World $(R)$. One sector produces a single homogeneous good, while a second sector produces a continuum of differentiated goods. Utility is given by:

$$
U=q_{0}^{\mu}\left(\int_{\Omega} q(\omega)^{\frac{\sigma-1}{\sigma}} d \omega\right)^{(1-\mu) \frac{\sigma}{\sigma-1}}
$$

where $q_{0}$ is the quantity of the homogeneous good consumed; $q(\omega)$ is consumption of each differentiated product variety $\omega \in \Omega ; \mu$ and $(1-\mu)$ are the respective consumption weights of the two sectors; and $\sigma$ is the elasticity of substitution among varieties within the differentiated goods sector.

Production in the homogeneous sector is subject to constant returns to scale, with one unit of labor input in region $i \in\{F, R\}$ producing $\bar{w}$ units of output, while one unit of labor in region $H$ produces $\underline{w}$ units of output. I assume that $H$ is a low productivity (developing) region, while $F$ and $R$ are high productivity (developed) regions. Thus, $\bar{w}$ $>\underline{w}$. The price of the homogeneous good is normalized to unity and trade is costless, which means that the wage in $H$ is $\underline{w}$ and in $F$ and $R$ it is $\bar{w}$.

In the differentiated goods sector, the $\operatorname{cost} c$ of producing $q$ units in region $i$ and selling them in region $j$ is:

$$
c_{i j}(q)=\frac{w_{i}}{\varphi} q+f_{i j}
$$

where $f_{i j}$ is the fixed cost of accessing the market in region $j$ for firms in region $i$. I conceptualize $f_{i j}$ as the design and retooling costs a firm in $i$ must pay in order to satisfy product standards in $j$ and thereby gain access to its market. ${ }^{18}$ For expositional clarity, and in line with this paper's focus on the extensive margin, there are no variable trade costs. Firms are heterogeneous in productivity $\varphi$, which is drawn from a Pareto distribution with support $[1,+\infty)$, shape parameter $\gamma>\sigma^{-1}$, and $\operatorname{CDF} G(\varphi)=P(\widetilde{\varphi<\varphi})=1-\varphi^{-\gamma}$.

\footnotetext{
${ }^{18}$ I treat product standards as exogenously imposed, and do not consider any role they might play on the consumption side (Ganslandt and Markusen 2001) or any strategic interactions that may arise between regions (Gandal and Shy 2001).
} 
Labor is the only factor of production, and each region is endowed with $L_{i}$ units. The model does not assume free entry as in Baller's (2007) two country model, but keeps the mass of potential entrants in each region fixed and proportional to $w_{i} L_{i}$. Total expenditure in each region $Y_{i}$ is thus the sum of labor income $w_{i} L_{i}$ and redistributed profits $w_{i} L_{i} \pi$, where $\pi$ is the dividend per share of a global mutual fund owned by labor ( $w_{i}$ shares per worker). Under standard assumptions, firm exports from region $i$ to region $j$ are equal to:

$$
x_{i j}(\varphi)=(1-\mu) Y_{j}\left(\frac{p_{i j}(\varphi)}{P_{j}}\right)^{1-\sigma}
$$

where $p_{i j}(\varphi)=\left(\frac{\sigma}{\sigma-1}\right)\left(\frac{w_{i} \tau_{i j}}{\varphi}\right)$ is the firm's optimal price; and $P_{j}$ is the CES price index for region $j$. Net firm profits from producing in region $i$ and selling in region $j$ are:

$$
\pi_{i j}(\varphi)=\left[p_{i j}(\varphi)-c_{i j}(\varphi)\right] q_{i j}(\varphi)-f_{i j}
$$

\section{B. Baseline Equilibrium}

Chaney (2008) describes in full the solution of the above model and its equilibrium properties. For present purposes, the most important result is that firms self-select into markets based on productivity. In equilibrium, zero profit conditions of the type $\pi_{i j}\left(\bar{\varphi}_{i j}\right)=0$ implicitly define a productivity cutoff condition of the following form for each market dyad:

$$
\begin{gathered}
\bar{\varphi}_{i j}=\lambda_{4}\left(\frac{Y}{Y_{j}}\right)^{\frac{1}{\gamma}}\left(\frac{w_{i}}{\theta_{j}}\right) f_{i j}^{\frac{1}{\sigma-1}} \\
\lambda_{4}=\left[\frac{\sigma}{\mu}\left(\frac{\gamma}{\gamma-(\sigma-1)}\right)\left(\frac{1}{1+\lambda_{5}}\right)\right]^{\frac{1}{\gamma}} \\
\lambda_{5}=\frac{\left(\frac{\sigma-1}{\gamma}\right) \frac{(1-\mu)}{\sigma}}{1-\left(\frac{\sigma-1}{\gamma}\right) \frac{(1-\mu)}{\sigma}}
\end{gathered}
$$




$$
\theta_{j}^{-\gamma}=\sum_{k \in\{H, F, R\}} \frac{Y_{k}}{Y}\left(w_{k}\right)^{-\gamma} f_{k j}^{-\left[\frac{\gamma}{(\sigma-1)-1}\right]}
$$

The equilibrium cutoff, $\bar{\varphi}_{i j}$, represents the minimum level of firm productivity consistent with profitably exporting from $i$ to $j$. Firms with $\varphi \leq \bar{\varphi}_{i j}$ become exporters, while those with $\varphi>\bar{\varphi}_{i j}$ do not. To be consistent with the observation that firms generally enter their domestic market first, and that only some domestic producers also export, I impose $f_{k k}<f_{l m}, \forall\{k, l \neq m\}$. One motivation for this condition is that foreign exporters need to obtain costly information on the nature of the importing country's standards before they can comply with them, meaning that there is always a differential between the compliance costs faced by domestic firms, and those faced by overseas competitors. As it is clear from the form of the cutoff condition, stricter or more numerous standards in the importing country-i.e., an increase in the fixed cost of compliance-mean that relatively low productivity exporters are pushed out of the market, while high productivity firms can continue exporting $\left(\frac{d \bar{\varphi}_{i j}}{d f_{i j}}>0\right.$, ignoring indirect effects).

The $\theta_{j}$ term can be interpreted as an index of region $j$ 's remoteness, similar to the inward multilateral resistance term of Anderson and van Wincoop (2003). Intuitively, the more remote a region is from the world as a whole, the lower the productivity barrier that a potential exporter must break through for a given level of bilateral trade costs $\left(\frac{d \bar{\varphi}_{i j}}{d \theta_{j}}<1\right)$. This result simply reflects the fact that it is relative costs, and thus relative trade barriers, that matter.

\section{Harmonization Equilibrium}

Harmonization takes the form of the adoption by $F$ of $R$ 's standard. Following harmonization, firms in $F$ and $R$ can access both regions upon compliance with the new harmonized standard and payment of the fixed cost $f_{R R}$. Firms in $H$ can now access $F$ and $R$ upon compliance with $R$ 's standard only, and thus payment of a single fixed cost, $f_{H R}$. Intuitively, it is obvious that the impact of harmonization depends on at least two forces that can act in different directions. On the one hand, accessing a larger market upon payment of a single fixed cost is suggestive of a scale effect that should make it easier to enter the export market, and thus increase trade at the extensive margin. However, the relative levels of fixed costs in $F$ and $R$ prior to harmonization also play a vital role in determining the outcome: the scale effect could be potentially undone if harmonization 
results, in effect, in the adoption by $F$ of a much more costly standard.

It is straightforward to derive the equilibrium conditions under harmonization from Equations (5) through (8) above. For the harmonizing regions $F$ and $R$, the new productivity cutoffs are:

$$
\begin{gathered}
\bar{\varphi}_{F F}^{\prime}=\bar{\varphi}_{R R}^{\prime}=\bar{\varphi}_{F R}^{\prime}=\bar{\varphi}_{R F}^{\prime}=\lambda_{4}\left(\frac{Y}{Y_{F}+Y_{R}}\right)^{\frac{1}{\gamma}}\left(\frac{\bar{w}}{\theta_{R}^{\prime}}\right) f_{R R}^{\frac{1}{\sigma-1}} \\
\left(\theta_{R}^{\prime}\right)^{-\gamma}=\left(\theta_{F}^{\prime}\right)^{-\gamma}=\frac{Y_{F}+Y_{R}}{Y} \bar{w}^{-\gamma} f_{R R}^{-\left[\frac{\gamma}{(\sigma-1)-1}\right]}+\frac{Y_{H}}{Y} \underline{w}^{-\gamma} f_{H R}^{-\left[\frac{\gamma}{(\sigma-1)-1}\right]}
\end{gathered}
$$

which reflects the fact that firms in either region can now access both regions upon payment of $f_{R R}$ and without any additional costs. Similarly, the excluded region $H$ 's cutoffs for exports to the harmonizing regions are:

$$
\bar{\varphi}_{H F}^{\prime}=\bar{\varphi}_{H R}^{\prime}=\lambda_{4}\left(\frac{Y}{Y_{F}+Y_{R}}\right)^{\frac{1}{\gamma}}\left(\frac{\underline{w}}{\bar{\theta}_{F}^{\prime}}\right) f_{H R}^{\frac{1}{\sigma-1}}
$$

with $\theta_{F}^{\prime}$ defined as above. Thus, firms in $H$ can access the combined $F$ and $R$ market upon payment of $f_{H R}$.

To identify the impact of harmonization on insiders and outsiders, I compare the export productivity cutoffs from $F$ to $R$ and from $H$ to $F$ prior to and following harmonization. The first comparison demonstrates the impact of harmonization on the harmonizing regions (insiders), while the second takes account of spillover effects to non-harmonizing regions (outsiders). Proceeding in this way makes it possible to identify three effects that act in different directions depending on the initial level of fixed costs and the way in which harmonization is implemented. I refer to these as the scale effect, the cost effect, and the remoteness effect.

From above:

$$
\frac{\bar{\varphi}_{F R}^{\prime}}{\bar{\varphi}_{F R}}=\left(\frac{Y_{R}}{Y_{F}+Y_{R}}\right)^{\frac{1}{\gamma}} \times\left(\frac{f_{R R}}{f_{F R}}\right)^{\frac{1}{\sigma-1}} \times\left(\frac{\theta_{R}}{\theta_{R}^{\prime}}\right)
$$




$$
\frac{\bar{\varphi}_{H F}^{\prime}}{\bar{\varphi}_{H F}}=\underbrace{\left(\frac{Y_{F}}{Y_{F}+Y_{R}}\right)^{\frac{1}{\gamma}}}_{\text {Scale Effect }} \times \underbrace{\left(\frac{f_{H R}}{f_{H F}}\right)^{\frac{1}{\sigma-1}}}_{\text {Cost Effect }} \times \underbrace{\left(\frac{\theta_{F}}{\theta_{F}^{\prime}}\right)}_{\text {Remoteness Effect }}
$$

In both cases, it is obvious that the scale effect must always lie between zero and unity, regardless of the initial values of the fixed cost parameters or the way in which harmonization is implemented. Since the comparison is in terms of productivity cutoffs, this means that the scale effect tends to produce a lower productivity cutoff in all countries following harmonization. This result makes obvious intuitive sense: harmonization effectively expands the market available to firms in all regions.

For the insiders $F$ and $R$, the cost effect acts in the same direction as the scale effect: it must lie between zero and unity since $f_{R R}<f_{F R}$ by assumption. Intuitively, this result reflects an effective cost reduction for producers in $F$ : instead of having to treat $R$ as a foreign market, and thus pay a relatively high entry cost, they can now effectively treat it as a domestic market.

The cost effect for the outsider $H$, on the other hand, depends on initial conditions. One possibility is that $F$ and $R$ initially have different but equally burdensome (costly) standards, i.e., $f_{H R}=f_{H F}$. I refer to this scenario as harmonization across, since it represents a horizontal move to an equally restrictive standard, rather than a vertical move to a more or less restrictive one. In this case, the cost effect simply cancels out, because the cost of accessing $R$ or $F$ does not change for $H$.

A more interesting case is harmonization up: $F$ 's standard is initially less burdensome (costly) than $R$ 's, so harmonization implies an increase in restrictiveness. In this scenario, $f_{H R}>f_{H F}$. As a result, the cost effect is greater than unity: harmonization brings about an increase in the cost for firms in $H$ of accessing the market in $F$, and so the minimum productivity cutoff moves up.

In the absence of indirect effects via the remoteness terms, ${ }^{19}$ harmonization always results in a lower productivity cutoff for insiders. The effect on outsiders, however, is ambiguous: the stronger the scale effect (i.e., the larger the combined market of $F$ and $R$ ) and the weaker the cost effect (i.e., the smaller the cost increase when $F$ harmonizes up to $R$ 's standard), the more likely it is that the overall effect will be to lower the

\footnotetext{
${ }^{19}$ More formally, the remoteness effect can be ignored in a more general model with a large number of countries and $H, F$, and $R$ all small, since $\frac{\theta_{R}}{\theta_{R}^{\prime}} \approx 1$ and $\frac{\theta_{F}}{\theta_{F}^{\prime}} \approx 1$.
} 
productivity cutoff for outsiders too.

Analysis of the indirect impacts of harmonization through the remoteness terms makes the situation somewhat more complex. For the case of trade between the insiders $F$ and $R$, the remoteness effect can be written as:

$$
\frac{\theta_{R}}{\theta_{R}^{\prime}}=\left[\frac{\frac{Y_{H}}{Y} \underline{w}^{-\gamma} f_{H R}^{-\left[\frac{\gamma}{(\sigma-1)-1}\right]}+\frac{Y_{F}}{Y} \bar{w}^{-\gamma} f_{F R}^{-\left[\frac{\gamma}{(\sigma-1)-1}\right]}+\frac{Y_{R}}{Y} \bar{w}^{-\gamma} f_{R R}^{-\left[\frac{\gamma}{(\sigma-1)-1}\right]}}{\frac{Y_{H}}{Y} \underline{w}^{-\gamma} f_{H R}^{-\left[\frac{\gamma}{(\sigma-1)-1}\right]}+\frac{Y_{F}}{Y} \bar{w}^{-\gamma} f_{R R}^{-\left[\frac{\gamma}{(\sigma-1)-1}\right]}+\frac{Y_{R}}{Y} \bar{w}^{-\gamma} f_{R R}^{-\left[\frac{\gamma}{(\sigma-1)-1}\right]}}\right]
$$

The remoteness effect tends to increase the productivity cutoff if harmonization leads to an overall decrease in remoteness, i.e., if $\theta_{R}>\theta_{R}^{\prime}$. In fact, this will always be the case for the two insiders because $f_{R R}<f_{F R}$ by assumption, which means that $f_{R R}^{\left[\frac{\gamma}{(\sigma-1)-1}\right]}>f_{F R}^{-\left[\frac{\gamma}{[(\sigma-1)-1}\right]}$. It follows that the denominator of the expression in brackets must be greater than the numerator, and thus $\frac{\theta_{R}}{\theta_{R}^{\prime}}>1$. Intuitively, harmonization between large regions decreases the weighted average level of their trade barriers with respect to all potential exporters. By bringing them closer to the world as a whole, harmonization makes it more difficult for firms in $F$ to export to $R$ for a given level of absolute bilateral costs due to the change this brings about in the level of relative trade costs.

For the outsider $H$, the corresponding effect is:

$$
\frac{\theta_{F}}{\theta_{F}^{\prime}}=\left[\frac{\frac{Y_{H}}{\underline{w}^{-\gamma}} f_{H F}^{-\left[\frac{\gamma}{(\sigma-1)-1}\right]}+\frac{Y_{F}}{Y} \bar{w}^{-\gamma} f_{F F}^{-\left[\frac{\gamma}{(\sigma-1)-1}\right]}+\frac{Y_{R}}{Y} \bar{w}^{-\gamma} f_{R F}^{-\left[\frac{\gamma}{(\sigma-1)-1}\right]}}{\frac{Y_{H}}{Y} \underline{w}^{-\gamma} f_{H F}^{-\left[\frac{\gamma}{(\sigma-1)-1}\right]}+\frac{Y_{F}}{Y} \bar{w}^{-\gamma} f_{R R}^{-\left[\frac{\gamma}{(\sigma-1)-1}\right]}+\frac{Y_{R}}{Y} \bar{w}^{-\gamma} f_{R R}^{-\left[\frac{\gamma}{(\sigma-1)-1}\right]}}\right]
$$

which varies in terms of its substantive effect according to whether the situation is one of harmonization across or harmonization up. In the former case, $f_{F F}=f_{R R}$ and $f_{R F}>$ $f_{R R}$ by assumption. Thus, the denominator of the expression in parentheses is greater than the numerator, as above, and it must be the case that $\frac{\theta_{F}}{\theta_{F}^{\prime}}>1$. So in the harmonization across case, the remoteness effect tends to raise the productivity cutoff. Again, the intuition is that harmonization decreases the overall level of trade barriers affecting imports into $F$, and thus for a given level of fixed costs between $H$ and $F$, it becomes 
relatively more difficult for $H$ 's exporters to access $F$ 's market.

In the case of harmonization up, the impact of the remoteness effect on the outsider $H$ is ambiguous because $f_{R R}^{-\left[\frac{\gamma}{(\sigma-1)-1}\right]}<f_{F F}^{-\left[\frac{\gamma}{(\sigma-1)-1}\right]}$ but $f_{R R}^{-\left[\frac{\gamma}{(\sigma-1)-1}\right]}>f_{R F}^{-\left[\frac{\gamma}{(\sigma-1)-1}\right]}$. For the symmetric case $Y_{R}=Y_{F}$, the impact of the remoteness effect depends on the relative differences between $f_{R R}$ and $f_{F F}$ versus $f_{R R}$ and $f_{R F}$. For a sufficiently small initial difference in domestic market entry costs between $F$ and $R$, and a sufficiently large initial difference in the cost of domestic entry in $R$ versus the cost of exporting from $R$ to $F$, the condition $\frac{\theta_{F}}{\theta_{F}^{\prime}}>1$ holds, and the remoteness effect tends to raise the productivity cutoff.

More generally, though, the impact of the remoteness effect for $H$ must be regarded as ambiguous. The cost differences discussed in the symmetric case still operate even when the regions are asymmetric, but the difference between $Y_{R}$ and $Y_{F}$ is also now crucial. From the form of the cutoff conditions, it is clear, however, that for a given level of cost differences, $Y_{R}$ sufficiently large relative to $Y_{F}$ ensures that the $f_{R R}^{-\left[\frac{\gamma}{(\sigma-1)-1}\right]}>f_{R F}^{-\left[\frac{\gamma}{(\sigma-1)-1}\right]}$ inequality dominates and that the remoteness effect tends to raise the productivity cutoff. For this paper, the $Y_{R}>Y_{F}$ context is particularly relevant, because it is international harmonization-i.e., adoption by one country of a standard prevailing internationallythat is examined empirically.

\section{Consolidation}

This Appendix has presented a simple theoretical framework for analyzing the impacts of product standards and harmonization on the extensive margin of trade. The model shows that the impact of harmonization on the extensive margin of trade depends on the interactions between three different effects: a scale effect, since harmonization creates a larger internal market between the harmonizing regions; a cost effect, since the harmonized standard can in some cases be more burdensome than the initial unharmonized standards; and a remoteness effect, which takes relative price effects into account.

The model highlights the fundamental distinction between insiders - the harmonizing regions - and outsiders. Abstracting from indirect (remoteness) effects, harmonization is always beneficial at the extensive margin for the insiders. However, its impact is ambiguous for outsiders, and depends on the relative strength of the market size and cost effects (see Table 4 for a recapitulation). 